\title{
Postpartum visits in the gynecological emergency room: How can we improve?
}

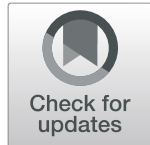

Alina Weissmann-Brenner ${ }^{1,2^{*}+}$, Ishai Heusler ${ }^{1,2+}$, Renana Manteka ${ }^{1,2}$, Mordechai Dulitzky ${ }^{1,2}$ and Micha Baum ${ }^{1,2}$

\begin{abstract}
Background: The attendance to the gynecological-emergency-room (GER) of women only a few weeks following previous discharge after birth comprises a medical as well as social problem. The objective of the study was to characterize the postpartum women that attended the GER, and depict the leading etiologies and risk-factors that lead them to attend the GER, and to examine correlations between their medical findings at discharge and the reasons for their attendance to the hospital.

Methods: All women that attended the GER between 01/01/2016 and 30/09/2016 during 6 weeks after birth were included. The variables assessed were: medical history, mode of birth, maternal complications of birth, diagnosis at the GER, treatment received and readmission.

Results: There were 446 visits of 413 women (5.6\% of all deliveries). Most were generally healthy after their first normal vaginal birth with no complications during or following birth. $38.7 \%$ had a cesarean birth $(p<0.001)$. The most common causes of the visits were fever (30.3\%), problems in episiotomy or surgical scar (26.6\%) and abdominal pain (25.7\%). Women with hypertensive disorders during birth had significantly more hypertensive problems in the GER. Diabetic women suffered statistically more from hypertensive disorder in the GER. 33.2\% were examined and found healthy. Seventy-two women (1\% of all deliveries) were hospitalized, most of them due to infection. Only $7.5 \%$ were referred to the GER due to bleeding.

Conclusions: Postpartum women are at risk of morbidities, especially following cesarean sections and in women with hypertensive disorders of during pregnancy. Scheduled visits to high-risk women to attend outpatient clinic sooner are recommended.
\end{abstract}

Keywords: Postpartum, Gynecological emergency room, Cesarean birth, Hypertensive disorders

\section{Background}

The postpartum period, defined as the first 42 days following birth, is characterized by many maternal physiological as well as emotional and social changes. Many mothers have insufficient knowledge about adequate postpartum care, the possible complications and the preventive measures or treatment modalities in cases of illnesses $[1,2]$.

Several studies focused on parenting support in the postpartum period, and emphasized the importance of

\footnotetext{
* Correspondence: alinabrenner@yahoo.com

'Weissmann-Brenner Alina and Heusler Ishai contributed equally to this work. ${ }^{1}$ Chaim Sheba Medical Center, Tel HaShomer Hospital, Ramat Gan, Israel

${ }^{2}$ Faculty of Medicine, Tel Aviv University, Tel Aviv, Israel
}

continuity of treatment after discharge following delivery $[1,2]$. However, there is insufficient data regarding maternal care during this vulnerable period. A wide range of physiological changes that occur in the postpartum period may mask illnesses. For example, fatigue, anxiety, stress, depression and sleep disorders may mask anemia, infection or hypertension; vaginal bleeding may be normal but may also result from retained placenta; and urinary incontinence may be a sign of urinary tract infection [3-5].

The attendance of puerperal women to the gynecological emergency room (GER) only a few days or weeks following previous discharge after birth, comprises a medical as well as social problem. One study found that $27 \%$ of women

C C The Author(s). 2020 Open Access This article is licensed under a Creative Commons Attribution 4.0 International License, which permits use, sharing, adaptation, distribution and reproduction in any medium or format, as long as you give appropriate credit to the original author(s) and the source, provide a link to the Creative Commons licence, and indicate if changes were made. The images or other third party material in this article are included in the article's Creative Commons licence, unless indicated otherwise in a credit line to the material. If material is not included in the article's Creative Commons licence and your intended use is not permitted by statutory regulation or exceeds the permitted use, you will need to obtain permission directly from the copyright holder. To view a copy of this licence, visit http://creativecommons.org/licenses/by/4.0/ The Creative Commons Public Domain Dedication waiver (http://creativecommons.org/publicdomain/zero/1.0/) applies to the data made available in this article, unless otherwise stated in a credit line to the data. 
who had complicated pregnancies attended the GER post discharge following delivery. However, data regarding the types of complications that lead to women attending the GER is lacking [6]. The readmission rate is reported to be $1-2.16 \%$, with an increase over the years [7-13].

The objective of the study was to characterize the postpartum women that attended the GER, to describe the causes and medical diagnosis of their visits, treatment and hospitalization. Their previous hospitalization was analyzed with special emphasis on medical problems such as diabetes and hypertensive disorders during pregnancy and infections and bleeding during delivery as well delivery by cesarean section. Our goal was to identify women at increased risk for postpartum complications, and to improve the treatment, postpartum care and follow up of these vulnerable women.

\section{Methods}

The study population included all the women that attended the GER of the Chaim Sheba Medical Center between 01/01/2016 and 30/09/2016 during the 6 weeks following birth. The study was approved by the institutional review board (IRB) of the Chaim Sheba Medical center. Due to the retrospective nature of the study this IRB approved not to obtain informed consent.

Postpartum was defined as the first 6 weeks following birth as accepted in previous publications [12].

Inclusion criteria were women who delivered at the Chaim Sheba medical center that attended the GER in the first 6 weeks following birth.

Data was derived from the department's women database. Women's medical history, pregnancy outcomes, and medical data at admission to the GER are routinely entered into the hospital's database.

The variables assessed in the study were: maternal age, parity, medical history, mode of birth, maternal complications at birth, fever, examination before discharge following birth, reasons and diagnosis of the GER visits, treatment received at GER and hospitalization.

The definition of maternal infectious condition included fever accompanied by clinical signs and symptoms that resulted in antibiotics treatment during or following birth.

Hypertensive disorders included hypertensive disease as a background medical condition, and any pregnancy related hypertensive disorder (including pregnancy induced hypertension, preeclampsia and eclampsia), treatment with antihypertensive medications, and postpartum hypertensive disorder.

\section{Statistical analysis}

The method of analysis in this article is largely descriptive, presenting the study variables as percentages for dichotomous and categorical characteristics. Mean, standard deviation, median and range were calculated for continuous variables such as age and length of stay. Causes of visit to the hospital, medical diagnosis, treatment, hospitalization and length of stay were compared between women with and without infections, bleeding hypertensive disorders, diabetes during birth and birth by cesarean section. Distribution of complications following birth, and causes of visit to GER in women with subsequent normal and abnormal examination, were presented. Differences of the above mentioned variables between the groups were examined by Chi-squared tests in the case of categorical and dichotomous variables or when relevant, by Fisher's exact test. Unpaired T-test was used for the comparison of length of stay between the study groups. A value of $p<0.05$ was considered statistically significant.

\section{Results}

During the study period there were 7371 deliveries at the Chaim Sheba Medical center, 5502 (74.6\%) were normal vaginal deliveries, 1869 (25.3\%) cesarean sections and 412 (5.6\%) operative vaginal deliveries.

In total, 413 puerperal women attended the GER. Of them, 389 visited the GER once, 18 visited the GER twice, three women came three times to the GER and three women came four times to the GER at the first 6 weeks following their childbirth. Overall there were 446 visits to the GER by 413 women (5.6\% of all deliveries).

The characteristics of the study population are presented in Table 1 . Most of them were generally healthy after their first normal vaginal birth with no complications following birth. A high rate of $16.7 \%$ had diabetes. The characteristics of women' birth are presented in Table 2. Significantly more women delivered by a cesarean section (38.2\%), compared to the $25.3 \%$ in the entire population that delivered by cesarean section during the study period in our medical center. The 26 women (6.3\%) that had medical findings during their discharge from the hospital, had improving hematoma of cesarean scar, headache, improving leg edema, improving abnormal liver or renal functions in laboratory tests. Ten women out of the 26 that were discharged with medical findings (38.5\%) were readmitted to the hospital.

The reason for the GER visit, the medical diagnosis and the treatment are presented in Table 3. The most common causes were fever (30.3\%), problems in episiotomy or surgical scar (26.6\%) and abdominal pain (25.7\%). A third (34.7\%) were examined and found healthy, $56.4 \%$ needed medical treatment, and 72 women comprising $1 \%$ of all deliveries were hospitalized (comprising $16 \%$ of all visits to the GER and $17.4 \%$ of all the women), most of them due to infection.

We compared women who had abnormal examination at discharge following birth to women with normal examination, Table 4 , and found no differences in the 
Table 1 Distribution of demographic and selected clinical characteristics of the study population

\begin{tabular}{|c|c|c|}
\hline & No. & $\%$ \\
\hline & 413 & 100 \\
\hline \multicolumn{3}{|l|}{ Age } \\
\hline Average & $32.9 \pm 5.4$ & \\
\hline Median (range) & (19-54) 32 & \\
\hline $40>$ & 361 & 87.4 \\
\hline $40 \leq$ & 52 & 12.6 \\
\hline \multicolumn{3}{|l|}{ Gravidity } \\
\hline Average & $2.34 \pm 1.73$ & \\
\hline Median (range) & $(1-12) 2$ & \\
\hline \multicolumn{3}{|l|}{ Parity } \\
\hline 1 & 232 & 56.2 \\
\hline $2-4$ & 170 & 41.2 \\
\hline $5-11$ & 11 & 2.7 \\
\hline \multicolumn{3}{|l|}{ Medical history } \\
\hline Generally healthy & 247 & 59.8 \\
\hline Endocrine disease & 90 & 21.8 \\
\hline Neurological disease & 27 & 6.5 \\
\hline Pulmonary disease & 19 & 4.6 \\
\hline Gastrointestinal disease & 17 & 4.2 \\
\hline Gynecological disorder & 17 & 4.2 \\
\hline Mental disorder & 16 & 3.9 \\
\hline Hypertensive disorder & 13 & 3.1 \\
\hline Rheumatological disease & 8 & 1.9 \\
\hline Morbid obesity & 5 & 1.2 \\
\hline Urinary disease & 5 & 1.2 \\
\hline Oncological disease & 5 & 1.2 \\
\hline Cardiac disease & 4 & 1.0 \\
\hline Orthopedic problem & 4 & 1.0 \\
\hline Infectious disease & 3 & 0.7 \\
\hline Genetic disease & 2 & 0.5 \\
\hline \multicolumn{3}{|l|}{ Diabetes } \\
\hline No & 344 & 83.3 \\
\hline Yes & 69 & 16.7 \\
\hline GDMA1 & 42 & 10.2 \\
\hline GDMA2 & 24 & 5.8 \\
\hline PGD & 3 & 0.7 \\
\hline
\end{tabular}

GDM gestational diabetes mellitus $P G D$ pre-gestational diabetes

number of women who had complications following birth.

Characterization of women whose birth was complicated with infection, bleeding or hypertensive disorders is presented in Table 5. Significantly more women with
Table 2 Distribution of delivery related characteristics of the study population

\begin{tabular}{|c|c|c|}
\hline & No. & $\%$ \\
\hline \multicolumn{3}{|l|}{ Mode of delivery } \\
\hline NVD & 222 & 53.8 \\
\hline Vacuum & 27 & 6.5 \\
\hline Forceps & 4 & 1.0 \\
\hline Cesarean section & 160 & 38.7 \\
\hline \multicolumn{3}{|l|}{ Complications during delivery } \\
\hline No & 387 & 93.7 \\
\hline Fever & 8 & 1.9 \\
\hline Bleeding & 19 & 4.6 \\
\hline \multicolumn{3}{|l|}{ Episiotomy } \\
\hline No & 313 & 75.8 \\
\hline Yes & 100 & 24.2 \\
\hline \multicolumn{3}{|l|}{ Perineal tear } \\
\hline No & 291 & 70.5 \\
\hline Grade 1-2 & 117 & 28.3 \\
\hline Grade $2-4$ & 4 & 1.0 \\
\hline Cervical tear & 1 & 0.2 \\
\hline \multicolumn{3}{|l|}{ Obstetrical maneuvers } \\
\hline No & 395 & 95.6 \\
\hline Manual revision of uterine cavity & 13 & 3.1 \\
\hline Lysis of placenta & 5 & 1.2 \\
\hline \multicolumn{3}{|l|}{ Complications following delivery } \\
\hline No & 335 & 81.0 \\
\hline Yes & 78 & 18.9 \\
\hline Infection & 9 & 2.2 \\
\hline Hypertension & 8 & 1.9 \\
\hline Bleeding & 32 & 7.5 \\
\hline Urinary & 12 & 2.9 \\
\hline Placental residua & 9 & 2.2 \\
\hline SVT & 6 & 1.5 \\
\hline Complications of anesthesia & 4 & 1.0 \\
\hline Allergy & 1 & 0.2 \\
\hline Psychosis & 1 & 0.2 \\
\hline \multicolumn{3}{|l|}{ Medical findings during discharge } \\
\hline No & 387 & 93.7 \\
\hline Yes & 26 & 6.3 \\
\hline Discharge with antibiotics & 32 & 7.7 \\
\hline Early discharge due to maternal request & 5 & 1.2 \\
\hline \multicolumn{3}{|l|}{ Length of hospitalization stay (days) } \\
\hline Mean \pm SD & $4.0 \pm 3.3$ & \\
\hline Median (range) & $3.0(1-37)$ & \\
\hline
\end{tabular}

NVD normal vaginal delivery

SVT superficial vein thrombosis 
Table 3 Distribution of cause of referral to GER, medical diagnosis and treatment in the GER

\begin{tabular}{lll}
\hline & No. & $\%$ \\
\hline Cause of referral to GER & 125 & 30.3 \\
Fever & 106 & 25.7 \\
Abdominal pain & 62 & 15 \\
Bleeding & 48 & 11.4 \\
Problem in scar & 110 & 26.6 \\
Problem in episiotomy/tear & 68 & 16.5 \\
Neurological problems & 28 & 6.8 \\
Orthopedic problems & 17 & 4.1 \\
Hypertension & 11 & 2.7 \\
Gastrointestinal problem & 8 & 1.9 \\
Venous thromboembolism & 7 & 1.7 \\
Dermatological problem & 6 & 1.5 \\
$\quad$ Shortness of breath & 6 & 1.5 \\
Cardiac problem & 3 & 0.7 \\
Hemorrhoids & 2 & 0.5 \\
Urinary problem & 2 & 0.5 \\
Mental problem & &
\end{tabular}

\section{Medical diagnosis in GER}

Normal examination

Infection

Bleeding

Hypertension

Problem in scar/episiotomy/tear

Abdominal pain

Neurological problem

Placental residua

Urinary problem

Venous thromboembolism

Other $^{\mathrm{b}}$

Need for medical consultants in GER

No

Yes

Treatment in GER

No need of treatment

Medical treatment

Removal of stich

Treatment of scar

Invasive/operative treatment

Insertion/removal of catheter

Other

\section{Medical treatment in GER}

No need

Antibiotics
$\%$

30.3

25.7

15.0

11.4

26.6

16.5

6.8

4.1

2.7

1.9

17

1.5

1.5
Table 3 Distribution of cause of referral to GER, medical diagnosis and treatment in the GER (Continued)

\begin{tabular}{lll}
\hline & No. & $\%$ \\
\hline Analgesia & 58 & 14 \\
Antihypertensive medications & 12 & 2.9 \\
Uterotonic medications & 13 & 3.1 \\
Treatment of hemorrhoids & 5 & 1.2 \\
Antipsychotic medications & 2 & 0.5 \\
Blood products & 1 & 0.2 \\
Other & 20 & 4.8 \\
Surgical treatment & & 99.3 \\
No & 410 & 0.7 \\
Yes & 3 & 0.2 \\
Blood Patch & 1 & 0.2 \\
Angiography & 1 & 0.2 \\
Dilatation and curettage & 1 & 3.6 \\
Self discharge from GER & 398 & \\
No & 15 &
\end{tabular}

Hospitalization following GER visit

No

$341 \quad 82.6$

Yes

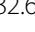

Causes of hospitalization

$\begin{array}{lll}\text { Infection } & 43 & 59.7\end{array}$

$\begin{array}{lll}\text { Bleeding } & 9 & 12.5\end{array}$

Problems in scar/episiotomy /tear $\quad 5 \quad 6.9$

$\begin{array}{lll}\text { Hypertension } & 8 & 11.1\end{array}$

$\begin{array}{lll}\text { Neurological problems } & 8 & 11.1\end{array}$

$\begin{array}{lll}\text { Venous thromboembolism } & 2 & 2.8\end{array}$

$\begin{array}{lll}\text { Placental residua } & 2 & 2.8\end{array}$

Mental problems $\quad 1 \quad 1.4$

Abdominal pain $\quad 1 \quad 1.4$

$\begin{array}{lll}\text { Ascites } & 1 & 1.4\end{array}$

Department of hospitalization

Gynecology $\quad 69 \quad 97.3$

$\begin{array}{lll}\text { Surgery } & 2 & 2.8\end{array}$

Neurology 11.4

${ }^{\mathrm{a} G E R}$ Gynecological Emergency Room

bOther: ascites, dermatological problems, gastrointestinal problems,

mental problems

hypertensive disorders during pregnancy visited the GER and were readmitted to the hospital $(p<0.001)$.

Comparison of reasons for GER visits, treatment and hospitalization in women following cesarean birth and in women with diabetes are presented in Figs. 1 and 2, respectively. The statistically significant causes of their GER visits were problems in the cesarean scar or episiotomy 
Table 4 Distribution of complications during delivery and causes of referral to GER in patients with subsequent normal and abnormal examination in the GER

\begin{tabular}{|c|c|c|c|c|c|}
\hline & \multicolumn{2}{|c|}{ Normal examination } & \multicolumn{2}{|c|}{ Abnormal examination } & \multirow[t]{3}{*}{$P$} \\
\hline & No. & $\%$ & No. & $\%$ & \\
\hline & 143 & 100 & 270 & 100 & \\
\hline \multicolumn{6}{|l|}{ Complications following delivery } \\
\hline No complications & 113 & 79 & 222 & 82.2 & \multirow[t]{9}{*}{0.6} \\
\hline With complications & 24 & 16.7 & 54 & 20 & \\
\hline Infections & 4 & 2.8 & 4 & 1.5 & \\
\hline Hypertensive disorders & 3 & 2.1 & 5 & 1.8 & \\
\hline Bleeding & 7 & 4.9 & 23 & 8.5 & \\
\hline Placental residua & 3 & 2.1 & 6 & 2.2 & \\
\hline Superficial vein thrombosis & 2 & 1.4 & 2 & 0.7 & \\
\hline Urinary problems & 4 & 2.8 & 8 & 3 & \\
\hline Other $^{a}$ & 1 & 0.7 & 7 & 2.6 & \\
\hline \multicolumn{6}{|l|}{ No. of complications } \\
\hline 1 & 21 & 14.7 & 51 & 18.9 & \multirow[t]{3}{*}{0.4} \\
\hline 2 & 3 & 2.1 & 2 & 0.7 & \\
\hline 3 & 0 & & 1 & 0.4 & \\
\hline \multicolumn{6}{|l|}{ Cause of referral to GER } \\
\hline Infection & 25 & 17.5 & 100 & 37 & $<0.001$ \\
\hline Bleeding & 27 & 18.9 & 35 & 13 & 0.06 \\
\hline Hypertensive disorder & 3 & 2.1 & 14 & 5.2 & 0.13 \\
\hline Problem in episiotomy & 48 & 33.6 & 62 & 23 & 0.006 \\
\hline Problem in scar & 17 & 11.9 & 31 & 11.5 & 0.7 \\
\hline Abdominal pain & 25 & 17.5 & 81 & 30 & 0.015 \\
\hline Neurological problem & 20 & 14 & 48 & 17.8 & 0.5 \\
\hline Orthopedic problem & 7 & 4.9 & 21 & 7.8 & 0.3 \\
\hline Gastrointestinal problems & 6 & 4.2 & 5 & 1.8 & 0.12 \\
\hline Venous thromboembolism & 3 & 2.1 & 5 & 1.8 & 0.5 \\
\hline Other & 9 & 6.3 & 17 & 6.3 & 0.9 \\
\hline
\end{tabular}

aOther: Anesthesia, abdominal pain, allergy and psychosis Mental, urinary, cardiac, dermatological problems, shortness of breath, hemorrhoids

and of abdominal pain. No increased rate of bleeding or infection was found in these women.

Significantly more women with diabetic complications utilized the GER due to hypertensive disorders, and needed treatment in the GER $(p<0.001)$.

\section{Discussion}

The present study demonstrated that $5.6 \%$ of all postpartum women visited the GER during the 6 weeks following birth. The most common causes of the GER visits were fever, abdominal pain and problems in episiotomy or surgical scar, and to a lesser extent vaginal bleeding. While hypertension and its complication were more common in women with known hypertensive disorders during pregnancy, most women were discharged without any complaints or clinical findings on examination.
Infection may be considered a major clinical risk in the postpartum women. A third of the women in the present study were diagnosed with an infectious condition in the GER. Similarly, Belfort et al., in their study of postpartum readmissions, reported that most of the reasons for readmission were infections [11]. Yokoe et al. described that $94 \%$ of postpartum infections became manifest only after the discharge from the hospital discharge [13]. We found more visits to the GER due to infections in women previously treated for infectious conditions immediately following childbirth, but this was not statistically significant. Caregivers may not reinforce women's intake of medications following discharge. Women may stop medications such as antibiotics if they feel well, or they may not take the prescribed dose, therefore causing relapse of infection. Furthermore, 
Table 5 Causes of referral to the hospital, medical diagnosis, treatment and hospitalization in patients by presence of infections, bleeding and hypertensive disorders during delivery

\begin{tabular}{|c|c|c|c|c|c|c|c|c|c|c|c|c|c|c|c|}
\hline \multirow[b]{4}{*}{ Total } & \multicolumn{5}{|c|}{ Hypertensive disorders } & \multicolumn{5}{|c|}{ Bleeding } & \multicolumn{5}{|c|}{ Infections } \\
\hline & \multicolumn{2}{|c|}{ Yes } & \multicolumn{2}{|c|}{ No } & \multirow[t]{3}{*}{$P$} & \multicolumn{2}{|c|}{ Yes } & \multicolumn{2}{|l|}{ No } & \multirow[t]{3}{*}{$P$} & \multicolumn{2}{|c|}{ Yes } & \multicolumn{2}{|l|}{ No } & \multirow[t]{3}{*}{$P$} \\
\hline & $\%$ & $\mathrm{n}$ & $\%$ & $n$ & & $\%$ & $n$ & $\%$ & $n$ & & $\%$ & $n$ & $\%$ & $n$ & \\
\hline & 26 & 100 & 387 & 100 & & 51 & 100 & 362 & 100 & & 38 & 100 & 375 & 100 & \\
\hline \multicolumn{16}{|l|}{ Cause of referral to GER } \\
\hline Infection & 5 & 19.2 & 120 & 31.0 & 0.15 & 16 & 31.4 & 109 & 30.1 & 0.8 & 15 & 39.5 & 110 & 29.3 & 0.2 \\
\hline Bleeding & 0 & & 62 & 16.0 & 0.01 & 8 & 15.7 & 54 & 14.9 & 0.9 & 7 & 18.4 & 55 & 14.7 & 0.5 \\
\hline Hypertension & 13 & 50.0 & 4 & 1.0 & 0.001 & 4 & 7.8 & 13 & 3.6 & 0.15 & 0 & & 17 & 4.5 & 0.2 \\
\hline Abdominal pain & 7 & 26.9 & 99 & 25.6 & 0.5 & 15 & 29.4 & 91 & 25.1 & 0.5 & 9 & 23.7 & 97 & 25.9 & 0.8 \\
\hline Problem in scar & 2 & 7.7 & 46 & 11.9 & 0.4 & 2 & 3.9 & 46 & 12.7 & 0.04 & 6 & 15.8 & 42 & 11.2 & 0.4 \\
\hline Problem in episiotomy & 3 & 11.5 & 107 & 27.6 & 0.05 & 7 & 13.7 & 103 & 28.5 & 0.03 & 11 & 28.9 & 99 & 26.4 & 0.7 \\
\hline Shortness of breath & 2 & 7.7 & 4 & 1.0 & 0.05 & 1 & 2.0 & 5 & 1.4 & 0.5 & 1 & 2.6 & 5 & 1.3 & 0.4 \\
\hline Neurological problem & 11 & 42.3 & 57 & 14.7 & 0.001 & 12 & 23.5 & 56 & 15.5 & 0.15 & 5 & 13.2 & 63 & 16.8 & 0.4 \\
\hline Other $^{a}$ & 1 & 3.8 & 57 & 14.7 & 0.2 & 4 & 7.8 & 54 & 14.9 & 0.2 & 6 & 15.8 & 52 & 13.9 & 0.8 \\
\hline \multicolumn{16}{|l|}{ Diagnosis in GER } \\
\hline Normal exam & 4 & 15.4 & 133 & 34.4 & 0.03 & 16 & 31.4 & 123 & 34.0 & 0.4 & 18 & 47.4 & 119 & 31.7 & 0.05 \\
\hline Infection & 4 & 15.4 & 99 & 25.6 & 0.18 & 16 & 31.4 & 87 & 24.0 & 0.3 & 11 & 28.9 & 92 & 24.5 & 0.5 \\
\hline Bleeding & 2 & 7.7 & 22 & 5.7 & 0.5 & 5 & 9.8 & 19 & 5.2 & 0.16 & 2 & 5.3 & 22 & 5.9 & 0.6 \\
\hline Hypertension & 15 & 57.7 & 0 & & $<0.001$ & 2 & 3.9 & 13 & 3.6 & 0.6 & 0 & & 15 & 4.0 & 0.2 \\
\hline Problem in scar/episiotomy & 1 & 3.8 & 62 & 16.0 & 0.07 & 4 & 7.8 & 59 & 16.3 & 0.08 & 4 & 10.5 & 59 & 15.7 & 0.3 \\
\hline Other $^{a}$ & 1 & 3.8 & 54 & 13.9 & 0.2 & 10 & 19.6 & 45 & 12.4 & 0.2 & 3 & 7.9 & 52 & 13.9 & 0.4 \\
\hline \multicolumn{16}{|l|}{ Treatment in GER } \\
\hline Yes & 16 & 61.5 & 218 & 56.3 & 0.6 & 30 & 58.8 & 204 & 56.4 & 0.7 & 16 & 42.1 & 218 & 58.1 & 0.057 \\
\hline No & 10 & 38.5 & 169 & 43.7 & & 21 & 41.2 & 158 & 43.6 & & 22 & 57.9 & 157 & 41.9 & \\
\hline \multicolumn{16}{|l|}{ Hospitalization } \\
\hline Yes & 10 & 38.5 & 62 & 16.0 & 0.004 & 13 & 25.5 & 59 & 16.3 & 0.08 & 5 & 13.2 & 67 & 17.9 & 0.3 \\
\hline No & 16 & 61.5 & 325 & 84.0 & & 38 & 74.5 & 303 & 83.7 & & 33 & 86.8 & 308 & 82.1 & \\
\hline
\end{tabular}

${ }^{a}$ Other: orthopedic, cardiac, urinary, gastrointestinal problems, hemorrhoids, venous thromboembolism

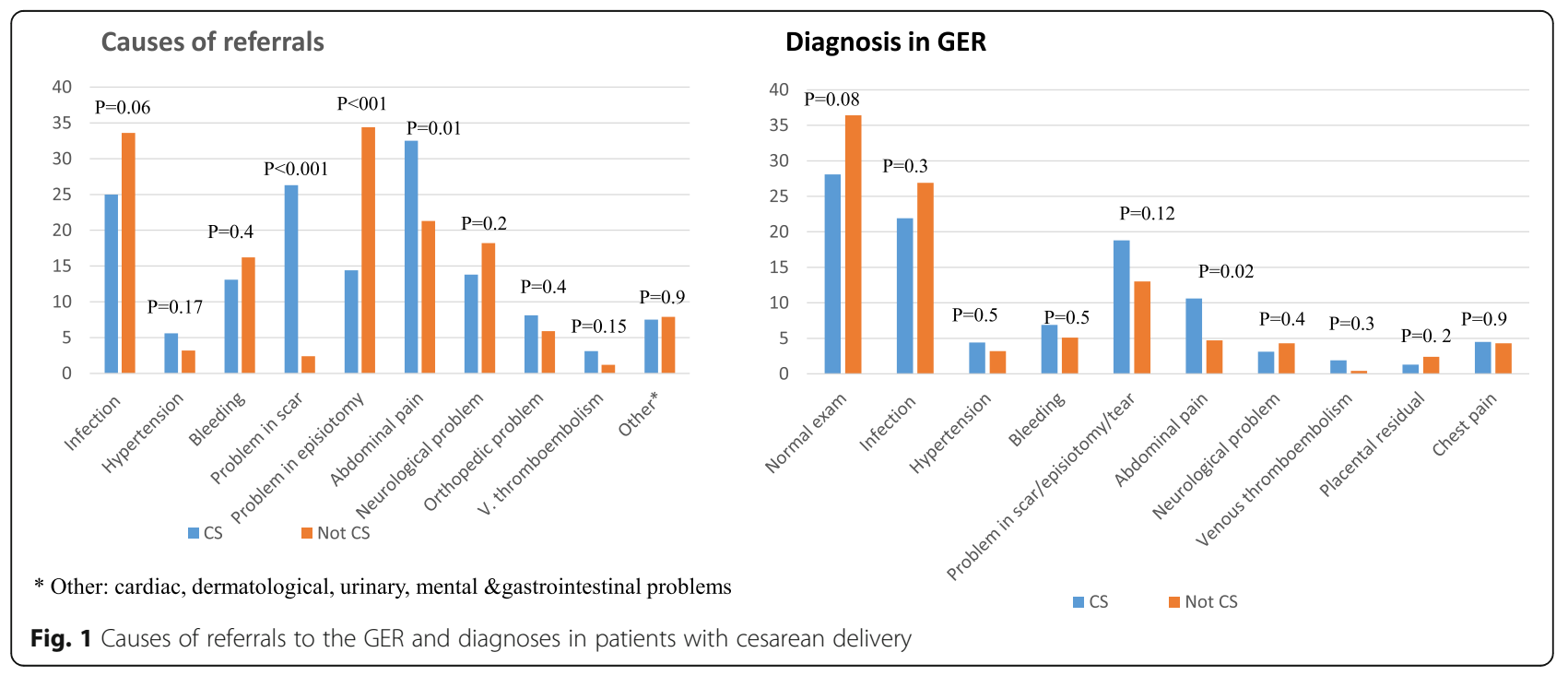




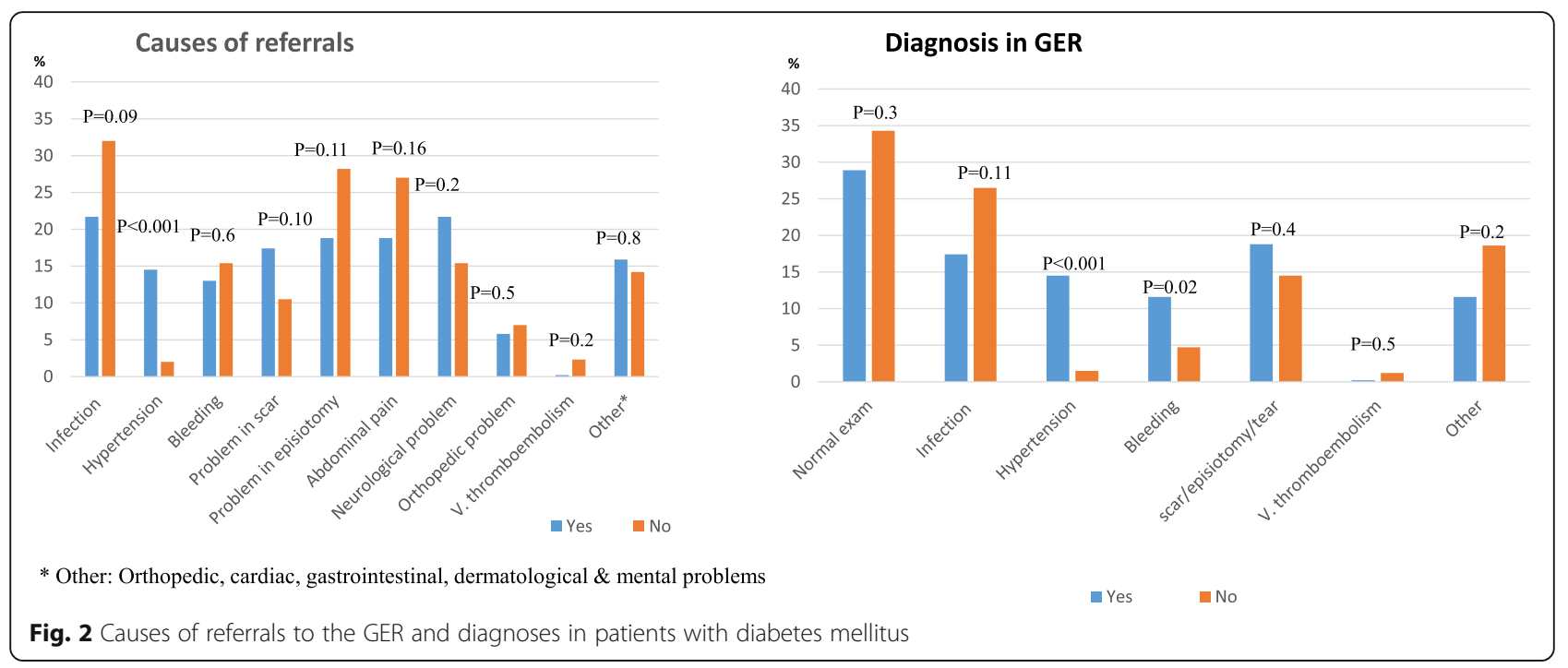

previous studies suggested that the immediate postpartum period may be a time of generalized immune suppression, thereby placing these women at increased risk of infection [12, 14-17]. Increased attention and explanation of the importance of the intake of medications should be given to the women prior to their discharge.

A similar challenge lies within women with hypertensive disorders. The present study demonstrated a statistically significant higher rate of hypertensive disorders in the women who attended the GER and suffered from hypertension during pregnancy or following birth. Previous studies report that women with hypertension had a higher proportion of acute care visits and higher rates of hospitalization in the postpartum period, including 11$44 \%$ rates of postpartum eclampsia [18, 19]. Some women are discharged with antihypertensive medications. Here too we are limited in the verification of the women' compliance to medications. Health professionals cannot monitor the actual intake of anti-hypertensive drugs outside the hospital. Most of the postpartum women with hypertension in the GER in the present study needed treatment and a high rate of $38.5 \%$ were readmitted. More attention should be given to the health education of hypertensive women before discharge regarding intake of medications and early identifications of hazardous signs of preeclampsia.

Similar to previous studies, the present study demonstrated that the mode of birth also poses a risk for postpartum visits in the GER, with statistically more women who delivered by a cesarean section visited the GER. The statistically significant reasons for their visits to the GER were abdominal pain, problems in the scar and problems in the episiotomy. The $21.9 \%$ rate of infection in women following cesarean section found in our study is similar to previous studies [10, 20-22].
We found a significantly higher rate of $16.7 \%$ of women with diabetes mellitus that visited the GER compared to the rate of $6-7 \%$ of diabetes in the general population [23]. Most of them suffered from hypertensive disorders and needed treatment in the GER. Similarly, Harris et al. and Clapp et al. reported more visits to the GER and more hospital readmissions in women whose pregnancies were complicated with diabetes mellitus [6] [9].

Medical problems necessitating visits to the GER pose a great burden on the women herself, her close environment and the medical system. Visit to the emergency room costs approximately 230 Ero $(257 \$)$. Visit to the outpatient clinic costs approximately 38Ero (43\$), making the visit to an outpatient clinic more cost effective. An earlier visit to an outpatient clinic should be recommended in high risk women with hypertensive disorders, infections, diabetes and following cesarean sections.

We acknowledge several limitations in our study: We did not analyze information regarding who referred the women to the GER. Therefore we do not have information on potential treatment in outpatient clinics. Referrals to outpatient clinics may decrease the GER visits. However, our study demonstrated a similar rate of GER visits as previously reported by Clark et al. and Brown et al. (4.8 and $7.8 \%$, respectively $[3,13])$. Furthermore, in a recent study Vikstrom al demonstrated that although women were scheduled planned follow-up visits during the first week following birth, $50 \%$ of the GER visits were unplanned [22].

\section{Conclusions}

Fever, abdominal pain, problems in episiotomy or surgical scar, and vaginal bleeding were the most common causes of the GER visits found in the present study. 
Postpartum women following cesarean sections and women with hypertensive disorders during pregnancy are at increased risk of comorbidities in the postpartum period. We recommend meticulous explanations to the women both in the hospital before discharge and in the outpatient clinics regarding the postpartum care in both vaginal and cesarean deliveries. Special emphasis should be made on the adherence to medical treatment received at home, in order to avoid physical deterioration. Scheduled visits to high-risk women to attend outpatient clinic sooner are recommended.

\section{Abbreviation}

GER: Gynecological-emergency-room

\section{Acknowledgements}

Not applicable.

\begin{abstract}
Authors' contributions
All of the authors have made substantial contributions to the concept, data interpretation, drafting or critical revision of the manuscript for intellectual content and have approved the final version. There are no conflicts of interest for the authors. All authors have read and approved the manuscript. WBA: Initialization, data collection, statistical analysis, writing of manuscript and revisions. HI: data collection, statistical analysis. MR: data collection. DM: Initialization, data collection, statistical analysis, writing of manuscript. BM: Initialization, data collection, statistical analysis, writing of manuscript and revisions.
\end{abstract}

\section{Funding}

No Funding was given regarding the present manuscript.

\section{Availability of data and materials}

The datasets used and/or analysed during the current study are available from the corresponding author on reasonable request.

\section{Ethics approval and consent to participate}

The study was approved by the institutional review board of the Chaim Sheba Medical center. Data was derived from the department's women database. Women's medical history, pregnancy outcomes, and medical data at admission to the GER are routinely entered into the hospital's database.

All authors have permission to enter this database.

\section{Consent for publication}

Not applicable.

\section{Competing interests}

The authors declare that they have no competing interests.

Received: 28 April 2019 Accepted: 7 April 2020

Published online: 07 May 2020

\section{References}

1. Barimani M, Vikström A. Successful early postpartum support linked to management, informational, and relational continuity. Midwifery. 2015;31(8): 811-7.

2. Barimani M, Vikström A. Improving postnatal care in Sweden - midwives have a key role. Sex Reprod Healthc. 2018;16:78-9.

3. Clark SL, Belfort MA, Dildy GA, Englebright J, Meints L, Meyers JA, Frye DK, Perlin JA. Emergency department use during the postpartum period: implications for current management of the puerperium. Am J Obstet Gynecol. 2010;203(1):38.e1-6.

4. Triviño-Juárez JM, Romero-Ayuso D, Nieto-Pereda B, Forjaz MJ, CriadoÁlvarez JJ, Arruti-Sevilla B, Avilés-Gamez B, Oliver-Barrecheguren C, MellizoDíaz S, Soto-Lucía C, Plá-Mestre R. Health related quality of life of women at the sixth week and sixth month postpartum by mode of birth. Women Birth. 2017;30(1):29-39
5. Milani HS, Amiri P, Mohseny M, Abadi A, Vaziri SM, Vejdani M. Postpartum home care and its effects on mothers' health: a clinical trial. J Res Med Sci. 2017;22:96.

6. Harris A, Chang HY, Wang L, Sylvia M, Neale D, Levine D, Bennett W. Emergency room utilization after medically complicated pregnancies: a Medicaid claims analysis. J Women's Health (Larchmt). 2015;24(9):745-54.

7. Clapp MA, Little SE, Zheng J, Kaimal AJ, Robinson JN. Hospital-level variation in postpartum readmissions. JAMA. 2017;317(20):2128-9.

8. Clapp MA, Robinson JN, Little SE. The relationship between the rising cesarean delivery and postpartum readmission rates. J Perinatol. 2017;37(4): 355-9.

9. Clapp MA, Little SE, Zheng J, Robinson JN. A multi-state analysis of postpartum readmissions in the United States. Am J Obstet Gynecol. 2016; 215(1):113.e1-113.e10

10. Lydon-Rochelle M, Holt VL, Martin DP, Easterling TR. Association between method of delivery and maternal rehospitalization. JAMA. 2000;283(18): 2411-6.

11. Belfort MA, Clark SL, Saade GR, Kleja K, Dildy GA 3rd, Van Veen TR, Akhigbe E, Frye DR, Meyers JA, Kofford S. Hospital readmission after delivery: evidence for an increased incidence of nonurogenital infection in the immediate postpartum period. Am J Obstet Gynecol. 2010;202(1):35.e1-7.

12. Thung SF, Norwitz ER. Postpartum care: we can and should do better. Am J Obstet Gynecol. 2010;202(1):1-4.

13. Brown HK, Cobigo V, Lunsky Y, Vigod S. Postpartum acute care utilization among women with intellectual and developmental disabilities. J Women's Health. 2017;26(4):329-37.

14. Yokoe DS, Christiansen CL, Johnson R, Sands KE, Livingston J, Shtatland ES, Platt R. Epidemiology of and surveillance for postpartum infections. Emerg Infect Dis. 2001;7(5):837-41.

15. Narita M, Yamada S, Kikuta H, Togashi T. Reconstitution of humoral immunity during pregnancy. Am J Reprod Immunol. 2000;44(3):148-52.

16. Elenkov IJ, Wilder RL, Bakalov VK, Link AA, Dimitrov MA, Fisher S, Crane M, Kanik KS, Chrousos GP. IL-12, TNF-alpha, and hormonal changes during late pregnancy and early postpartum: implications for autoimmune disease activity during these times. J Clin Endocrinol Metab. 2001;86(10):4933-8.

17. Singh N, Perfect JR. Immune reconstitution syndrome and exacerbation of infections after pregnancy. Clin Infect Dis. 2007:45(9):1192-9.

18. Garg D, Rahaman B, Stein EG, Dickman E. Late postpartum Eclampsia with postpartum Angiopathy: an uncommon diagnosis in the emergency department. J Emerg Med. 2015;49(6):e187-91.

19. Hamilton MS, Brooten D, Youngblut JM. High-risk pregnancy: postpartum rehospitalization. J Perinatol. 2002;22(7):566-71.

20. Kawakita T, Landy HJ. Surgical site infections after cesarean delivery: epidemiology, prevention and treatment. Matern Health Neonatol Perinatol. 2017;3:12.

21. Liu S, Heaman M, Joseph KS, Liston RM, Huang L, Sauve R, Kramer MS. Maternal health study Group of the Canadian Perinatal Surveillance System. Risk of maternal postpartum readmission associated with mode of delivery. Obstet Gynecol. 2005;105(4):836-42.

22. Vikström A, Johansson SE, Barimani M. Postnatal ER visits within 30 dayspattern, risk factors and implications for care. J Clin Nurs. 2018;27(3-4):769-76.

23. Gabbe SG, Niebyl JR, Simpson JL, Landon MB, Galan HL, Jauniaux ERM, Driscoll DA, Berghella V, Grobman WA. Obstetrics: Normal and Problem Pregnancies, Elsevier 7th Edition. 2016. p. 878.

\section{Publisher's Note}

Springer Nature remains neutral with regard to jurisdictional claims in published maps and institutional affiliations. 